\title{
AÇÕES EDUCATIVAS VOLTADAS PARA A PROMOÇÃO DO ALEITAMENTO MATERNO NO MUNICÍPIO DE MARTINS-RN: UM RELATO DE EXPERIÊNCIA
}

\author{
Anna Karla Fausto MAIA ${ }^{1}$ \\ Lívia Dourado MAGALHÃES ${ }^{2}$ \\ Ionara de Souza JANUÁRIO ${ }^{3}$ \\ Edivania Fernandes de SOUSA ${ }^{4}$
}

\begin{abstract}
${ }^{1}$ Enfermeira. Diretora do Centro de Saúde do Município de Martins-RN. Especialista em assistência e Gestão em Saúde da Família e Auditoria. Mestranda em Gestão Hospitalar e Saúde Coletiva pela Faculdade do Norte do Paraná. E-mail: akarla-maia@ hotmail.com

${ }^{2}$ Enfermeira. Pós-graduanda em Saúde do Idoso e Gerontologia pela Universidade Cândido Mendes. E-mail: liviamagalhaes_jd@hotmail.com

${ }^{3}$ Enfermeira. Pós-graduanda em Enfermagem em Terapia Intensiva pela Faculdade Metropolitana de Ciência e Tecnologia. E-mail: ionara_76@hotmail.com

${ }^{4}$ Advogada. Procuradora do Município de Martins. Especialista em Gestão em Saúde pela Universidade Federal do Rio Grande do Norte. E-mail: edivaniaadv@gmail.com
\end{abstract}

Recebido em: 30/09/2014 - Aprovado em: 30/11/2014 - Disponibilizado em: 15/12/2014

\section{RESUMO}

OBJETIVO: descrever a experiência vivenciada pela Equipe de Enfermagem em um grupo de gestantes e puérperas, atendidas na Estratégia Saúde da Família de um bairro do município de Martins-RN. METODOLOGIA: trata-se de um estudo descritivo com abordagem qualitativa, do tipo relato de experiência, desenvolvido na Unidade Básica de Saúde da Família do município de Martins-RN, com um grupo de gestantes e puérperas quinzenalmente, entre os meses de Janeiro a Julho do ano de 2014. RESULTADOS E DISCUSSÃO:A enfermagem tem papel fundamental no que tange ao aleitamento materno, na prática de educação e saúde durante o pré-natal pode incentivar a amamentação precoce e exclusiva. As ações educativas realizadas no munícipio ocorrem através de rodas de conversas, sanando dúvidas e quebrado tabus, explanação acerca da importância da amamentação para o binômio mãe-filho, prática de yoga e demonstração da pega correta da amamentação. CONCLUSÃO: a prática de atividades educativas em saúde torna-se um instrumento eficaz de transformação da gestante e, por conseguinte da puérpera, a qual se deve educar considerando sempre a singularidade de cada uma, respeitando suas crenças e saberes popular.

Descritores: Enfermagem. Atenção Básica. Gestantes. Aleitamento Materno. Educação em Saúde.

\begin{abstract}
OBJECTIVE: describe the lived experience of the nursing team in a group of pregnant women and women who delivered in the Family Health Strategy in a neighborhood of the city of Martins-RN. METHODOLOGY: it is a descriptive study with a qualitative approach, the experience report, developed at the Basic Health Unit of the Municipality of Family-Martins RN, with a group of pregnant and postpartum women fortnightly, between the months of January to July of the year type 2014. RESULTS AND DISCUSSION: nursing has key role in relation to breastfeeding, the practice of education and health during the prenatal can encourage early and exclusive breastfeeding. The educational activities in the municipality occur through conversations wheels, solving doubts and broken taboos, explanation about the importance of breastfeeding for both mother and child, yoga practice and demonstration of proper latch breastfeeding. CONCLUSION: the practice of educational activities in health becomes an effective instrument of transformation of the pregnant woman and therefore the postpartum, which should always educate considering the uniqueness of each one, respecting their beliefs and popular knowledge.
\end{abstract}

Keywords: Nursing. Primary Care. Pregnant women. Breastfeeding. Health Education 


\section{INTRODUÇÃO}

$\mathrm{O}$ aleitamento materno constitui uma importante estratégia natural que favorece o vínculo entre o binômio mãe-filho, além de promover proteção e nutrição para a criança, compõe a mais sensível, econômica e eficaz intervenção para redução da mortalidade infantil. Estudos indicam que a amamentação exclusiva tem o potencial de reduzir em $13 \%$ as mortes por causas evitáveis em crianças menores de 5 anos, e em 19 a $22 \%$ as mortes neonatais, quando praticada na primeira hora de vida (JOVENTINO et al., 2011; VENANCIO et al., 2010).

A Organização Mundial da Saúde (OMS) e o Ministério da Saúde (MS) preconizam a amamentação exclusiva até sexto mês de vida do bebê, podendo esta servir de complemento até os dois anos ou mais de vida da criança. O MS incentiva a prática do aleitamento materno para os casos em que não exista contra-indicação e recomenda o desenvolvimento de ações pela atenção básica de saúde na promoção da amamentação (BRASIL, 2007; GUSMÃO et al., 2013).

No entanto, para efetivar a prática aleitamento materno exclusivo, são necessários esforços dos múltiplos segmentos sociais, em especial dos profissionais da saúde, visto que a ausência de orientação sobre o aleitamento materno está descrita na literatura como um dos fatores determinantes para sua interrupção precoce (MARTINS et al., 2011).

Nesse sentido, ressalta-se que os profissionais de saúde, em especial os Enfermeiros das Unidades Básicas de Saúde da Família (UBSF), desempenham um papel de extrema relevância na assistência integral à mulher-mãe-nutriz, principalmente quando se refere a sua sensibilização para a prática do aleitamento materno, haja vista que a amamentação é um processo complexo que abarca aspectos biológicos, psicológicos e sócio-culturais (JOVENTINO et al., 2011).

Para tanto, é necessário que os profissionais de saúde tenham sensibilidade e destreza tanto no manejo clínico da lactação como na técnica de aconselhamento, que é adquirida com a prática cotidiana, acrescentada pelos conhecimentos obtidos na graduação, capacitações e atualizações, que juntos devem ser o alicerce para uma assistência de qualidade (BEZERRIL, 2010).

A forma de educar, baseado na sensibilidade e empatia do profissional de saúde pode proporcionar uma melhor sensibilização das gestantes e puérperas acerca da importância do aleitamento materno, contribuindo assim para a redução do desmame precoce, promovendo qualidade de vida tanto para as lactantes quanto para os lactentes (BEZERRIL, 2010).

Nessa perspectiva, viu-se a necessidade da criação um grupo de gestantes e puérperas capaz de assistir de forma integral 
a mulher que vivência o período gravídicopuerperal, por meio de ações educativas que estimulam o aleitamento materno exclusivo. Desta forma, o presente estudo tem por objetivo descrever a experiência vivenciada pela equipe de enfermagem em um grupo de gestantes e puérperas, atendidas na Unidade Básica de Saúde da Família de um bairro do município de Martins - Rio Grande do Norte (RN).

\section{METODOLOGIA}

De acordo com os objetivos propostos no estudo, o qual envolve a descrição de características de uma determinada população, optou-se por desenvolver uma pesquisa descritiva com abordagem qualitativa, do tipo relato de experiência.

A pesquisa de cunho descritiva visa descrição das características de determinada população ou fenômeno ou ainda o estabelecimento de relações entre determinadas variáveis de investigações empíricas. No entanto, estudos desta natureza, podem transpassar a simples identificação destas variáveis, mas, no entanto, decorrem pela determinação da natureza dessa relação (Gil, 2008). Considerando que este tipo de pesquisa atendeu as exigências de análise, sendo a mais adequada sobre dados ou fatos colhidos na própria realidade para a investigação proposta pelo estudo.
O estudo foi desenvolvido no âmbito das experiências vivenciadas pela equipe de enfermagem de uma Unidade Básica de Saúde da Família localizada na zona urbana do município de Martins- RN. As atividades educativas com o grupo de gestantes e puérperas foram desenvolvidas pela equipe quinzenalmente em parceria com o NASF (Núcleo de Apoio a Saúde da Família), sob a coordenação da Enfermeira da unidade, no decorrer dos meses de Janeiro a Julho do ano de 2014.

\section{RESULTADOS E DISCUSSÃO}

A importância do aleitamento materno exclusivo para a preservação do bem estar do binômio mãe e filho é consenso na literatura brasileira. O leite materno, além de ser ideal por seu valor nutricional e imunobiológico para o recém-nascido, traz também benefícios para a mulher como, por exemplo, a redução do sangramento pós-parto, diminuição da ocorrência de anemias e redução dos índices de câncer de ovário e mama. No entanto, é sabido que a gestação, por ser uma experiência complexa e singular, pode deixar à gestante mais vulnerável aos mitos e tabus sobre o processo de amamentação, os quais devem ser sanados pela a equipe de saúde (AZEVEDO et al., 2010).

Neste sentido, estimular a amamentação exclusiva constitui-se como uma das principais ações realizadas pela 
equipe de saúde da Atenção Básica, e esta deve ocorrer desde o início do pré-natal até o puerpério. O Enfermeiro, por sua vez tem papel relevante no incentivo e na manutenção do aleitamento, ao realizar orientações e suportes para as gestantes e lactantes, para isso são necessários conhecimentos e habilidades no manejo das diversas fases da lactação. $\mathrm{O}$ aconselhamento no pré-natal assim como a orientação e ajuda no período de estabelecimento da amamentação são tarefas de responsabilidade da enfermagem, tendo em vista que é nesse período quese aumenta a probabilidade de surgir problemas relacionados com a prática da amamentação (CARVALHO et al., 2014).

A enfermagem tem papel fundamental no que tange a amamentação, na prática de educação e saúde durante o pré-natal pode incentivar a amamentação precoce e exclusiva de forma assertiva, ajudando a mulher a adquirir autoconfiança em sua capacidade de amamentar, promovendo qualidade $\mathrm{e}$ individualidade no processo de cuidar. Ressalta-se ainda a importância deste profissional, tendo em vista ser o mesmo que apresenta um vínculo mais estreito com as gestantes e puérperas, estabelecendo assim uma relação de confiança (CARVALHO; CARVALHO; MAGALHÃES, 2011).

Nessa perspectiva, uma das ações educativas realizadas pela equipe de enfermagem, no grupo de gestante e puérperas da Unidade Básica de Saúde da
Família do município de Martins- RN foi voltada para a prática do aleitamento materno, a qual constou de três momentos distintos.

O primeiro momento foi realizado na unidade com todas as gestantes e puérperas da área adscrita, com a presença de um educador físico que introduziu um alongamento utilizando a prática da yoga, com o objetivo de promover o relaxamento das usuárias. Logo em seguida foi iniciada uma roda de conversa com a Enfermeira da unidade, com uma apresentação de um portfólio baseado no álbum seriado "Promovendo o Aleitamento Materno" disponibilizado pelo MS, com intuito de explanar acerca da importância da amamentação para o binômio mãe-filho, enfatizando-se os benefícios do leite materno para ambos. Posteriormente foram realizados questionamentos sobre a temática, incentivando a participação do público presente a responderem o que mesmas sabiam sobre o aleitamento materno e suas possíveis dúvidas.

Muitos são os motivos que podem levar a interrupção do aleitamento materno. Dentre os motivos referidos pelas participantes do grupo está à necessidade de retomar ao trabalho, fissuras nas mamas, falta de paciência e condições socioeconômicas desfavoráveis, além das crenças populares de que o leite é fraco e não tem o suficiente para alimentar a criança e que a amamentação faz os seios caírem. Tal realidade demonstra a falta de conhecimento das participantes, 
impregnada de mitos e insegurança nessa nova fase de vida.

Consoante a isto, segundo Carvalho et al (2014), cabe ao enfermeiro por meio de um olhar sensível e abrangente identificar a presença de mitos e tabus presentes nesta fase, para poder atuar minimizando os conflitos entre os saberes científicos e os populares, direcionando-se assim da melhor forma a essas pacientes.

Depois de perceber a carência das informações durante a roda de conversa, foi possível sanar todos os mitos, tabus e dúvidas das gestantes e puérperas. Aproveitando o momento, para reforçar a importância da amamentação para a mãe e o bebê, enfatizando os benefícios do leite materno, e como deveria ser realizada a prática correta da amamentação, a qual se utilizou uma boneca para demonstrar as formas corretas de amamentar, cada gestante demostrou ao grupo como ela amamentaria. Dessa forma, a equipe pode visualizar os possíveis erros e assim orientar melhor sobre o posicionamento do bebê e a pega correta.

Nesse ínterim, percebe-se que a falta de conhecimentos, ou ainda informações errôneas são fatores decisivos para que as mulheres mais carentes decidam não amamentar, ou ainda abandonar precocemente esta prática. Apesar de muitas evidências científicas da superioridade do leite materno sobre outro leite, ainda é muito baixo o número de mulheres que amamentam seus filhos de acordo com as recomendações do MS e da OMS (MARTINS et al., 2011).

\section{CONCLUSÃO}

Desenvolver ações educativas voltadas para o aleitamento materno com o grupo de gestante e puérperas permitiu a equipe de enfermagem perceber a carência de informações que existia entre as participantes do grupo para um tema de fundamental relevância. Desta forma, foi oportuno desenvolver ações voltadas para o incentivo ao aleitamento materno, visto que essa prática traz benefícios tanto para a mulher quanto para o bebê, que tem uma maior probabilidade de tornar-se uma criança saudável e com um desenvolvimento adequado. Ademais, é evidente que a prática da educação em saúde é um dos principais componentes organizacionais da atenção primária a saúde.

No desenvolvimento das atividades educativas foi possível observar que todas as puérperas que participaram do grupo ofertado pela unidade de saúde, reconheciam as informações do aleitamento materno exclusivo, entretanto não sabiam explicitar as razões dessa importância, como também tinham informações errôneas e impregnadas de mitos.

A equipe de enfermagem da Atenção Básica exerce um papel fundamental frente ao suporte de incentivo ao aleitamento materno, 
uma vez que estabelece o contato precoce com a gestante na assistência do pré-natal, formando um vínculo de confiança, capaz de sensibilizar a gestante quanto à importância do aleitamento materno exclusivo, através do suporte e orientações necessárias, bem como através da resolubilidade das possíveis dúvidas dessas mulheres.

\section{REFERÊNCIAS}

ALMEIDA, N. A. M.; FERNANDES, A. G.;

DE ARAÚJO, C. G. Aleitamento materno: uma abordagem sobre o papel do enfermeiro no pós-parto. Revista Eletrônica de enfermagem, v. 6, n. 3, p. 358-367, 2004. Disponível em: <http://h200137217135.ufg.br/index.php/fen/ article/view/835/983 >. Acesso em: 24 Set 2014.

AZEVEDO, D. S. de. et al. Conhecimento de primíparas sobre os benefícios do aleitamento materno. Rev. Rene, v. 11, n. 2, p. 53-62, abri/jun 2010. Disponível em: < http://www.repositorio.ufc.br/bitstream/riufc/ 4382/1/2010_art_lvfreitas1.pdf> Acesso em 05 de setembro de 2014.

BRASIL. Ministério da Saúde. Secretaria de Atenção à Saúde. Promovendo o

Aleitamento Materno. Álbum seriado,2 Ed. Brasília: 2007. Disponível
Assim, os achados deste estudo indicam que a prática de atividades educativas em saúde torna-se um instrumento eficaz de transformação da gestante e, por conseguinte da puérpera, portanto, a ações educativas em saúde devem sempre ser realizadas considerando-se as particularidades e singularidade de cada uma, respeitando suas crenças e saberes popular.

em:<http://webcache.googleusercontent.com/ search?q=cache:F2VSQVezNA8J:www.fiocr uz.br/redeblh/media/albam.pdf $+\& \mathrm{~cd}=2 \& \mathrm{hl}=\mathrm{pt}$ -BR\&ct $=$ clnk\&gl=br $>$. Acesso em: 24 Set2014.

BEZERRIL, D. S. et al. Humanização do cuidado de Enfermagem a lactante: um estudo bibliográfico. Anais CBCENF. Rio Grande do Norte. 2010. Disponível em: <http://189.59.9.179/cbcenf/sistemainscricoes /arquivosTrabalhos/I18522.E8.T3220.D4AP.p df >. Acesso em 24 Set2014.

CARVALHO, J. K. M. de; CARVALHO, C. G.; MAGALHÃES, S. R. A importância da assistência de enfermagem no aleitamento materno. e-Scientia, Belo Horizonte, Vol. 4, N. ${ }^{\circ}$, p. 11-20, 2011.

CARVALHO, O. M. C.et al. Prevalência dos diagnósticos de enfermagem de amamentação no binômio mãe-filho em unidade básica de saúde. Rev Rene, v. 15, n. 1, p. 99-107, 
jan/fev2014. Disponível em:

<http://www.revistarene.ufc.br/revista/index.p hp/revista/article/view/1482>Acesso em 05 de setembro de 2014.

GIL, A. C. Métodos e técnicas de Pesquisa Social. 6 ed. São Paulo: Atlas, 2008.

GUSMAO, A. M. de. et al . Prevalência de aleitamento materno exclusivo e fatores associados: estudo transversal com mães adolescentes de 14 a 16 anos em Porto Alegre, RS, Brasil. Ciênc. saúde coletiva, Rio de Janeiro, v.18, n. 11, Nov 2013.

Disponível em: $<$ http://www.scielo.br/scielo.php?script=sci_a rttext\&pid=S1413$81232013001100025 \& \operatorname{lng}=$ en\&nrm=iso $>$. Acesso em 24 setembro 2014.

JOVENTINO, E. S. et al . Tecnologias de enfermagem para promoção do aleitamento materno: revisão integrativa da literatura. Rev. Gaúcha Enferm.

(Online), Porto Alegre, v. 32, n. 1, Mar 2011. Disponível em: $<$ http://www.scielo.br/scielo.php?script=sci_a rttext\&pid=S1983$14472011000100023 \& \operatorname{lng}=$ en\&nrm=iso $>$. Acesso em 24 Setembro 2014.

\section{MARTINS, C. da C. et al. Fatores de riscos} maternos e de assistência ao parto para interrupção precoce do aleitamento materno exclusivo: estudo de coorte. Rev Baiana De Saúde Pública, v. 35, supl.1, p.167-178, jan/jun 2011. Disponível em: <http://files.bvs.br/upload/S/01000233/2011/v35nSup11/a2307.pdf> Acesso em 20 de setembro de 2014.

VENANCIO, S. I. et al . A prática do aleitamento materno nas capitais brasileiras e Distrito Federal: situação atual e avanços. J. Pediatr. (Rio J.), Porto Alegre, v. 86, n. 4, Ago 2010. Disponível em: $<$ http://www.scielo.br/scielo.php? script=s ci_arttext\&pid=S0021-75572010000400012>. Acesso em 24 setembro 2014. 